\title{
MicroRNAs and Endothelial Dysfunction in Relation to Obesity and Type 2 Diabetes
}

Dwi Setyowati Karolina1, Maskomani Silambarasan', Arunmozhiarasi Armugam ${ }^{1}$ and Kandiah Jeyaseelan ${ }^{1,2 *}$

${ }^{1}$ Department of Biochemistry, Yong Loo Lin School of Medicine, Centre for Translational Medicine, National University of Singapore, 8 Medical Drive, Singapore ${ }^{2}$ Department of Anatomy and Developmental Biology, School of Biomedical Sciences, Faculty of Medicine, Nursing and Health Sciences, Monash University, Clayton, Victoria, Australia

\begin{abstract}
The vascular endothelium constitutes an important barrier for the selective passage of plasma proteins, solutes and fluid from the blood to the underlying interstitium and cells. In addition to that, the endothelium also regulates the production of various autocrine and paracrine factors in order to maintain vascular homeostasis. Hence, normal endothelial function is critical for proper vascular activity including blood vessel development and growth (angiogenesis), leukocyte trafficking, coagulation and fibrinolysis. Endothelial dysfunction results from the imbalance between vasoconstriction and vasodilation that predispose the vasculature to leukocyte adherence, endothelial proliferation as well as thrombosis. Several studies have demonstrated the implication of obesity and diabetes in the progression of endothelial dysfunction which in turn accelerates the manifestation of vascular complications. The coexistence between obesity, diabetes and endothelial dysfunction suggests the involvement of common regulators between the three entities. MicroRNAs are promising candidates of these regulators since they have the ability to control the expression of multiple genes that regulate our cellular processes. In fact, dysregulation of microRNAs is a common feature in various human diseases including obese/diabetes-associated vascular complications. This review describes the direct and indirect mechanisms of obesity and diabetes in relation to the manifestation of endothelial dysfunction. At the same time, it also summarizes the latest insights into the implications of microRNAs in the development of endothelial dysfunction and discusses their potential for the treatment of vascular pathophysiological conditions.
\end{abstract}

\section{Introduction}

Endothelial cells (EC) are quiescent, flat and mono-epithelial layer of cells that comprise the innermost lining of blood vessels which serves as an interface between the circulating blood and surrounding tissues. Extensive research over the last two decades has uncovered the complexity of this semi-permeable membrane and its sophisticated role in regulating vascular tone and structure. Under physiological conditions, the ECs act as a barrier to facilitate the selective transport of substances such as nutrients and leukocytes. At the same time, it also secretes several mediators to modulate vascular functioning, coagulation, immune responses as well as vascular growth [1]. Endothelial dysfunction refers to the inability of the endothelium to regulate vascular homeostasis and essentially describes a loss in the balanced release of endothelial-derived relaxing and contracting factors [2]. In recent years, endothelial dysfunction has received increasing attention as an early predictive marker of vascular disorders and that its manifestation precedes the appearance of significant clinical symptoms. Accumulating evidence suggests endothelial dysfunction as a commonality in obese and type 2 diabetes (T2D), the two main metabolic disorders that increase risk for cerebro-cardiovascular related morbidity and mortality [3]. In fact, obesity and insulin resistance, a hallmark of $\mathrm{T} 2 \mathrm{D}$, are considered as the major causal factors in the development of endothelial dysfunction. The study on the behaviour of the endothelium in health and disease has equipped us with a better understanding of how vascular damage develops, particularly in obese and T2D individuals. Elucidating the mechanisms responsible for the obesity/diabetes-associated endothelial dysfunction is highly important and will have a substantial clinical impact on future translational and interventional research.

MicroRNAs (miRNAs) are a class of naturally occurring, highly conserved, noncoding small RNAs that play a pivotal role in the regulation of gene expression to control a wide range of biological functions. With the advancing experimental strategies and robust bioinformatics databases available, a total of 30,424 mature miRNAs have been identified in 206 species (miRBase Release 20). In the human genome alone, 2578 miRNAs known to control more than $60 \%$ of the protein encoding genes have been identified [4,5]. In general, miRNAs regulate biochemical events by post-transcriptionally inhibiting the expression of a plethora of target genes. A steady-state level of the functional miRNAs is important in maintaining a normal physiological status of a cell or any biological system. Increasing mass of data has demonstrated that miRNAs can modulate endothelial phenotype [6]. Furthermore, loss of the modulatory role of miRNAs is a critical and initiating factor in the development of endothelial dysfunction. These new insights have shed light on the complex interplay between miRNAs and endothelial dysfunction in obesity and T2D. In the first part of this review, we describe the development of endothelial dysfunction in obesity and diabetes and how the three entities are interconnected. Following that, we illustrate the importance of miRNAs as modulators of endothelial function and with reference to the recent research reports, we address the role of miRNAs in obesity and diabetesassociated endothelial dysfunction.

*Corresponding author: Prof. Kandiah Jeyaseelan, Department of Biochemistry Yong Loo Lin School of Medicine, Centre for Translational Medicine, National University of Singapore, 8 Medical Drive, Singapore, Tel: +65-6516 3248; E-mail: bchjeya@nus.edu.sg

Received December 13, 2014; Accepted January 20, 2014; Published January 22, 2014

Citation: Karolina DS, Silambarasan M, Armugam A, Jeyaseelan K (2014) MicroRNAs and Endothelial Dysfunction in Relation to Obesity and Type 2 Diabetes. J Mol Genet Med S1: 011. doi: 10.4172/1747-0862.S1-011

Copyright: (c) 2014 Karolina DS, et al. This is an open-access article distributed under the terms of the Creative Commons Attribution License, which permits unrestricted use, distribution, and reproduction in any medium, provided the original author and source are credited 


\section{Endothelial Dysfunction in Diabesity}

Obesity and T2D are two sides of the same coin. Fuelled by rapid urbanization, globalization of food production and marketing as well as increasing physical inactivity in today's society, the prevalence of obesity has grown in parallel with T2D. This has even prompted researchers to coin a new hybrid term, diabesity, a constellation of metabolic disorders including obesity, insulin resistance, metabolic syndrome and diabetes [7]. Diabesity affects more than one billion people worldwide and is becoming the largest rapidly escalating pandemic in human history. At present, mortality from obesity and diabetes stand at approximately 2.8 and 4.6 million people respectively annually worldwide. Diabesity poses a major risk for chronic illnesses including cardiovascular disease (CVD) and stroke, among other medical problems [8]. In fact, several studies have shown that people with diabesity are more likely to develop cardiovascular complications even in the absence of CVD. Of the multiple causal factors accountable for this increased risk of CVD, perhaps the most important one is endothelial dysfunction, which resulted from continuous and progressive damage to the vascular wall by the aforementioned metabolic abnormalities.

\section{Endothelial function and dysfunction}

To maintain vascular homeostasis, ECs control a balanced release of components of the extracellular matrix namely collagen and various regulatory chemical mediators including nitric oxide (NO), prostanoids (prostacycline), endothelin-1 (ET-1), angiotensin II (ANG-II), tissuetype plasminogen activator (t-PA), plasminogen activator inhibitor-1 (PAI-1), von Willebrand factor (vWF), adhesion molecules (vascular cell adhesion molecule 1, VCAM; leukocyte adhesion molecule, LAM; intercellular adhesion molecule, ICAM) and cytokines such as tumor necrosis factor (TNF) [9]. No is one of the most important mediator produced in the conversion of amino acid 1-arginine to 1-citrulline by endothelial nitric oxide synthase (eNOS) in the ECs [10]. Due to its vasodilatory, anti-platelet, anti-proliferative, permeability-decreasing, anti-inflammatory and anti-oxidant properties, NO inhibits migration and adhesion of leukocytes as well as cytokine-induced expression of VCAM-1, monocyte chemoattractant protein-1 (MCP-1) by suppressing nuclear factor kappa-light-chain-enhancer of activated $\mathrm{B}$ cells $\left(\mathrm{NF}_{K_{K}} \mathrm{~B}\right)$ [11]. ECs regulate fibrinolysis by producing t-PA and its inhibitor PAI-1 while restricting the coagulation cascade by thrombomodulin/protein $\mathrm{C}$, heparin sulphate/antithrombin and tissue factor/tissue factor inhibitor interactions. Its implications on vascular remodeling are mediated by modulating the production of promoters and inhibitors of growth and differentiation of the vascular smooth muscle cells (VSMC), such as platelet-derived growth factor (PDGF) and ANG-II [12]. Regulatory effects of ANG-II on the VSMC activities include growth, proliferation, differentiation and contraction. Furthermore, regulatory inflammatory role of ECs is exerted via the release of adhesion molecules like LAM, ICAM and VCAM [13].

Endothelial dysfunction is established when factors that favour a vasoconstriction, pro-coagulation and pro-inflammation become predominant over mediators that facilitate vasodilation, anticoagulation and anti-inflammation [14]. This process is associated with reduction in NO production or activity as a result of oxidative stress [15]. Endothelial dysfunction is one of the earliest events that occur in the process of atherosclerosis [16,17]. A large body of evidence in humans indicates that endothelial dysfunction and diabesity coexist frequently $[18,19]$. The definitive pathogenesis of endothelial dysfunction in diabesity is not yet fully understood, possibly due to the multiple homeostatic imbalances that this population displays.
Nevertheless, several mechanisms pertaining to inflammation and insulin resistance have been proposed. On another note, obesity, specifically in the central or abdominal area, impairs endothelial function via direct and/or indirect mechanisms (Figure 1). Excess adiposity is often the insidious factor that leads to imbalanced release of various metabolic products, hormones and cytokines that induce inflammation and also compromise insulin sensitivity in the peripheral tissues (liver and skeletal muscles) [20,21].

\section{Obesity-associated endothelial dysfunction}

The adipose tissue modulates endothelial function via secretion of various hormones including adiponectin, resistin, leptin, PAI-1, angiotensin, estradiol and inflammatory cytokines such as TNF- $\alpha$ and interleukin 6 (IL-6) [3]. In the ECs, adiponectin induces NO production while suppressing oxidative stress and inflammatory signalling cascades through AMP-activated protein kinases (AMPK) and cyclic AMP-protein kinase A-linked pathway [22]. Anti-inflammatory effects of adiponectin are also mediated by suppressing the expression of adhesion molecules and reducing monocyte attachment to ECs $[23,24]$. However, plasma levels of adiponectin are found to be reduced in people with diabesity and/or those with diabesity-related diseases [25]. In contrast, other adipokines like PAI- 1 inflammatory cytokines such as TNF- $\alpha$ and IL-6 are over-expressed with obesity (Figure 1) [2629]. Inflammatory cytokines increase vascular permeability, impair vasoregulatory responses, induce leukocyte adhesion to endothelium and facilitate thrombus formation by activating pro-coagulant factors, inhibiting anti-coagulant pathways and impairing fibrinolysis via PAI-1 stimulation. PAI-1 is typically elevated in diabesity state and serves as a key factor in the genesis of vascular abnormalities. It has also been linked to the increased occurrence of thrombosis in patients with diabesity [30]. The role of resistin, another fat-derived hormone, is still under debate because although a number studies has reported increased resistin levels with increasing adiposity, a few others have stated otherwise $[31,32]$.

ANG-II in the adipose tissue also plays a role in the regulation of endothelial function. When this molecule binds to the angiotensin II type 1 receptor on ECs, it induces the expression of ICAM- 1 and promotes the release of reactive oxygen species (ROS) via nicotinamide adenine dinucleotide phosphate-oxidase (NADPH-ox) and ET-1 from the endothelium $[33,34]$. ROS function as important intra/intercellular second messengers to regulate endothelial function, VSMC growth and migration as well as vascular reactivity and integrity. Under pathophysiological conditions, increased bioavailability of creates a state of oxidative stress leading to vascular dysfunction and remodelling [35]. Simultaneously, angiotensin interferes with insulin signalling that is involved in production of NO and activation of eNOS in endothelium. Angiotensin-induced activation of c-Jun N-terminal kinase (JNK) and mitogen-activated protein kinase (MAPK) pathways in ECs results in reduced tyrosine phosphorylation and increased serine phosphorylation of insulin receptor substrate 1 (IRS-1) [36,37]. IRS-1 is a protein downstream of the insulin receptor that plays a significant role in insulin signalling and action, to mediate glucose uptake in fat cells and NO production in ECs. Proper tyrosine phosphorylation of this molecule is important for maintaining insulin signalling. Many studies have shown that phosphorylation of several serine residues on IRS- 1 reduces the ability of IRS- 1 to engage with the p 85 subunit of PI-3 kinase [37-39]. This subsequently attenuates insulin signalling which will have deleterious consequences on endothelial function. The other adipokine, TNF- $\alpha$, has been demonstrated to increase monocyte adhesion to the vascular endothelium [40], induce $\mathrm{NF}_{\mathrm{K}} \mathrm{B}$-dependent 


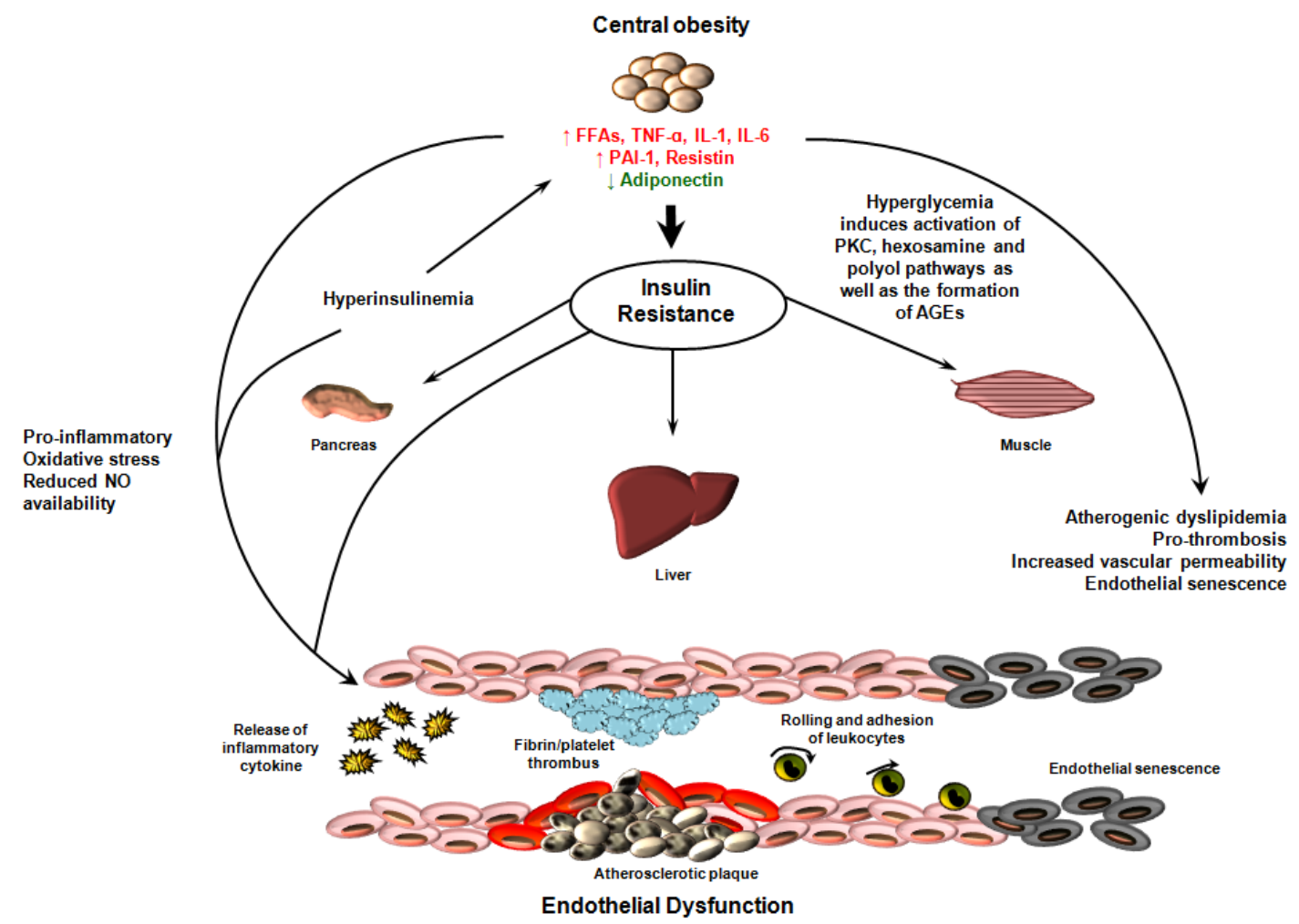

Figure 1: Obesity, type 2 diabetes and endothelial dysfunction. Direct and indirect mechanisms of obesity, insulin resistance and hyperglycaemia in relation to endothelial dysfunction as well as endothelial senescence. AGEs, advanced glycation end products; FFAs, free fatty acids; IL-1, interleukin1; IL-6, interleukin 6; NO, nitric oxide; PAI-1, plasminogen activator inhibitor 1; PKC, protein kinase C; TNF- $\alpha$, tumour necrosis factor $\alpha$.

pro-inflammatory pathways [41] as well as endothelial and smooth muscle expression of the adhesion molecule VCAM-1 [42] and matrix metalloproteinases respectively [43]. Collectively, these factors bring about endothelial dysfunction and plaque destabilization. TNF- $\alpha$ can also induce the expression of another powerful inflammatory cytokine, IL-6 which in turn induces hepatic production of C-reactive protein (CRP). CRP is a key molecule in the process of atherogenesis in ECs and increased level of plasma CRP has been found to predict CVD. CRP increases the expression of the endothelial ICAM-1, VCAM1, E-selectin, MCP-1 and ET1 secretion [44]. Furthermore, CRP also causes down-regulation of eNOS expression while inducing angiotensin receptor type 1 expression in the vessel wall [45]. This may sequentially have adverse effects on the vascular wall. Nonetheless, negative feedback of IL- 6 on TNF- $\alpha$ has also been reported and that interventions to increase IL- 6 were able to exert anti-inflammatory effect by suppressing TNF- $\alpha[46,47]$.

\section{Diabetes-associated endothelial dysfunction}

Insulin resistance and hyperglycemia are the two principal characteristics of T2D which are also implicated in endothelial dysfunction. Excess adipose tissue not only activates the inflammatory pathways but also contributes to the manifestation of insulin resistance which overall aggravates the progression of endothelial dysfunction. Several mechanisms of obesity-associated insulin resistance have been proposed and reviewed in detail by Qatanani and Lazar [48]. The underlying mechanisms are highly complex involving crosstalk between a plethora of molecules, systems and pathways that are interrelated. Such that when one pathway is disturbed, its interconnections with the others lead to perturbations in the other systems that exacerbate the problem. In a simplistic view, adipose mass predisposes to systemic insulin resistance through enhanced rates of lipolysis in the intra-abdominal adipocytes that lead to increased efflux of free fatty acids (FFAs) which in turn overloads the liver, skeletal muscles and pancreatic $\beta$ cells with lipids (Figure 1). The ectopic lipid accumulation and excess secretion of pro-inflammatory adipokines such as TNF- $\alpha$, resistin, PAI-1 and IL-6 dampen insulin action hence increasing insulin resistance, atherogenic dyslipidemia and hyperinsulinemia [49-52]. TNF- $\alpha$ has been implicated as the central molecule linking diabetes, insulin resistance, obesity and endothelial dysfunction. As already discussed above, this factor can induce the synthesis of other cytokines, which alone or in concert with the rest, may impair endothelial function.

In addition to its role in glucose homeostasis, insulin is also known as the vascular hormone that has both physiologic and pathophysiologic roles in the vasculature. Insulin stimulate NO and ET-1 production in the endothelium through signalling pathways such as the vaso protective phosphoinositide-3 kinase (PI3-K)/Akt pathway that is closely associated with insulin signalling [53]. Through this pathway, eNOS expression is induced and activated. eNOS facilitates the production of NO that is important in preventing atheroma formation. However, under pathological state as in T2D individuals, gluco toxicity, lipo toxicity and insulin resistance compromise the ability of insulin to stimulate NO production in ECs and also interfere with insulin signalling [54]. At the same time, production of ROS is increased which in turn accelerates the progression of vascular complications. Insulin also promotes the activation of MAPK/extracellular signal-regulated 
kinase (ERK) pathway which has a less beneficial outcome of cellular proliferation. Insulin resistance causes a selective deficiency of the PI3-K pathway while MAPK signalling pathway remains unaffected [55]. In fact, such selective resistance creates a state of hyper insulinemia that over stimulates MAPK signalling hence further promoting proatherogenic condition that is detrimental to the vasculature $[56,57]$.

Chronic hyper glycemia, another hallmark of diabetes, promotes endothelial dysfunction through four principal mechanisms; Protein kinase C (PKC) activation, activation of the hexosamine and polyol pathways as well as the formation of advanced glycation endproducts (AGEs) [58]. These pathways are believed to contribute to vascular damage via the unifying oxidative stress mechanism in which production of ROS exceeds the capacity of the anti-oxidant system to remove them [59]. Oxidative stress confers endothelial dysfunction by reducing NO bioavailability either through direct degradation by ROS, or by impairing the functional capacity of eNOS.

Under physiological conditions, the polyol and hexosamine pathways exhibit low affinity for glucose, but hyper glycemic condition leads to shunting of glucose through these pathways which results in $\mathrm{PKC}$ activation and alterations in properties of protein and DNA [60]. PKC in turn activates NADPH oxidase releasing more superoxide anion hence exerting further oxidative stress in the endothelium. Furthermore PKC activation also causes dysregulation of the vascular permeability through induction of VEGF, thickening of the basement membrane due to TNF- $\beta$-induced expression of Type IV collagen and fibronectin as well as up-regulation of PAI-1 which may impair fibrinolysis [23,61]. The polyol pathway metabolizes sorbitol (from excess glucose) to fructose, thereby inducing the oxidation of NADPH to $\mathrm{NADP}^{+}$and reduction of $\mathrm{NAD}^{+}$to $\mathrm{NADH}$, which results in decreased NO bioavailability $[62,63]$. This redox imbalance increases production of methylglyoxal and AGEs that can enhance oxidative stress. AGEs arise from intracellular hyperglycemia and subsequent non-enzymatic reactions also causing changes in protein function as well as modifications to the extracellular matrix [64]. Furthermore, activation of receptor for advanced glycation end products (RAGE) on the endothelium also contributes to ROS production, subsequently activating the $\mathrm{NF}_{-} \mathrm{B}$ pathway hence exacerbating atherogenic gene expression [65].

Although the precise molecular pathways governing vascular formation have yet to be unravelled, these reports provide insights on the synergistic interaction and vicious cycle that exist in which diabesity contributes to endothelial dysfunction and vice versa. In recent years, emerging research has revealed some endothelial-specific miRNAs to be involved in regulating the actions of ECs and the surrounding VSMCs that are fundamental to vascular structure and function. In the next part of the review, we look at the various aspects of miRNA regulatory network in pathologic state of the ECs, predominantly focusing on diabesity-associated mechanisms of endothelial dysfunction.

\section{Biogenesis and functions of MicroRNAs}

The initiation of miRNA biogenesis starts with transcription of miRNA genes into primary miRNA (pri-miRNAs) transcripts with

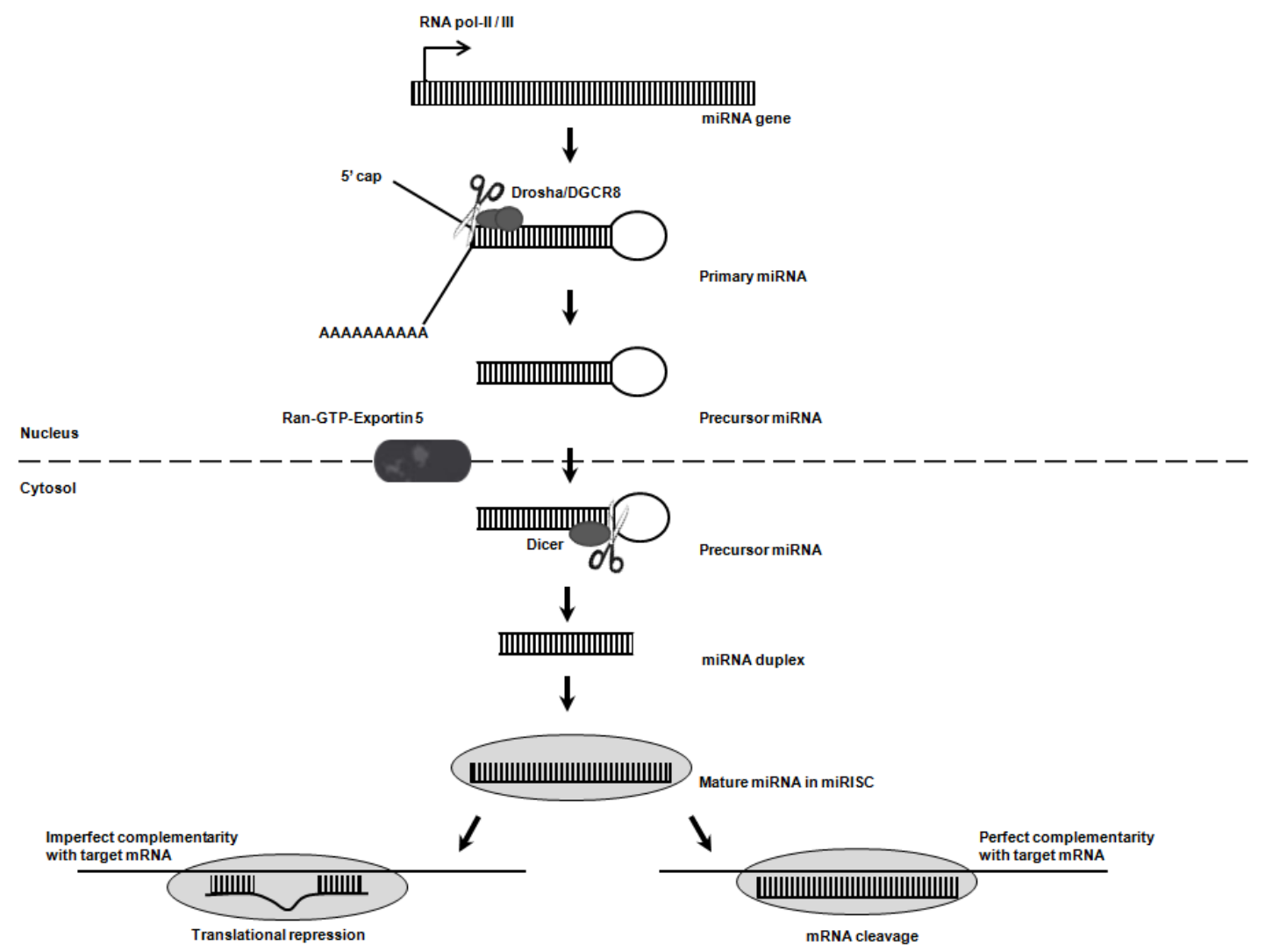

Figure 2: Biogenesis of microRNAs and their mechanism of action. miRNAs are transcribed into primary miRNAs by RNA polymerase I/II. Maturation of miRNAs is mediated by Drosha and Dicer. Imperfect base pairing of miRNA to its target mRNA results in translational blockage while perfect base pairing between the two leads to mRNA cleavage. 
the help of RNA polymerase II/III [66] (Figure 2). The pri-miRNAs fold into hairpin structure, which act as substrate for endonucleolytic cleavage by the RNase III enzymes, Drosha and DGCR8/Pasha. In this process, DGCR8 interact stably with the pri-miRNAs and acts as a molecular ruler to locate the precise cleavage site. It then orients the catalytic RNase III domain of Drosha to cleave the 5' and 3' arms of the stem loop hairpins. This produces an approximately 70 nucleotides long precursor miRNA (pre-miRNA) with 2-nucleotide 3'-overhang. The 2-nucleotide 3'-overhang of the pre-miRNA is then recognized by Exportin-5, a Ran-GTP-dependent nuclear export factor, to be exported into the cytoplasm [66]. In the cytoplasm, the pre-miRNA is further processed by Dicer to generate a miRNA-miRNA duplex ( 22-nucleotides) [67]. Of the duplex, the less thermodynamically stable 'guide strand' is incorporated into an RNA-induced silencing complex (RISC) to form the miRNA-RISC assembly which is responsible in executing regulatory functions of miRNAs. The other strand, known as the 'passenger strand' is degraded as a RISC complex substrate [68].

miRNAs generally act on their target mRNAs by binding to the 3'UTR and this interaction brings about inhibitory effects via two mechanisms (Figure 2). The first mechanism occurs via perfect binding with its target mRNA which results in mRNA cleavage and degradation. When the binding is imperfect, translational suppression takes place by which the miRNA-repressed mRNAs are engulfed into P-bodies for storage [69]. Although miRNAs are more widely known to inhibit the expression of its target genes, several studies have evidently demonstrated their role in gene activation [70,71]. Since the binding of miRNAs to their mRNA targets does not require exact complementarity, each miRNA displays a promiscuous character targeting more than 100 mRNAs. With the immense capacity to target multiple functionally related genes to control entire biological pathways, it is anticipated that aberrant miRNA expression would have adverse effects on the functioning of the biological system.

\section{MicroRNAs in diabesity-associated endothelial dysfunction}

Our previous review on miRNAs and diabetes mellitus summarised the wide range of miRNAs implicated in the pathogenesis of diabetes and obesity as well as those involved in the micro/macro-vascular complications [72]. Several other authors have also reported excellent reviews on the above subject [73-75]. In this review, we focus on the miRNAs implicated in diabesity-induced endothelial dysfunction. We have collated miRNAs that are involved and implicated in processes such as inflammation associated with obesity, insulin resistance, hyperglycemia as well as angiogenesis and endothelial senescence, the principal mechanisms in endothelial dysfunction (Figure 3).

The first evidence implicating miRNAs in vascular development was demonstrated by Yang et al. [76] who generated a deletion of the first and second exons of the Dicer gene $\left(\right.$ Dicer $\left.^{\text {ex1/2}}\right)$ in mice. These mice died between days E12.5 and E14.5 and exhibited defects in vascular formation. In the context of ECs, in vitro silencing of Dicer and Drosha by siRNA technique resulted in significant reduction in EC migration, capillary sprouting and tube formation [77]. Nonetheless, it was the silencing of Dicer but not Drosha that reduced angiogenesis in vivo. This is due to the altered expression of several factors regulating angiogenesis including endothelial cell-specific receptor kinase, vascular endothelial

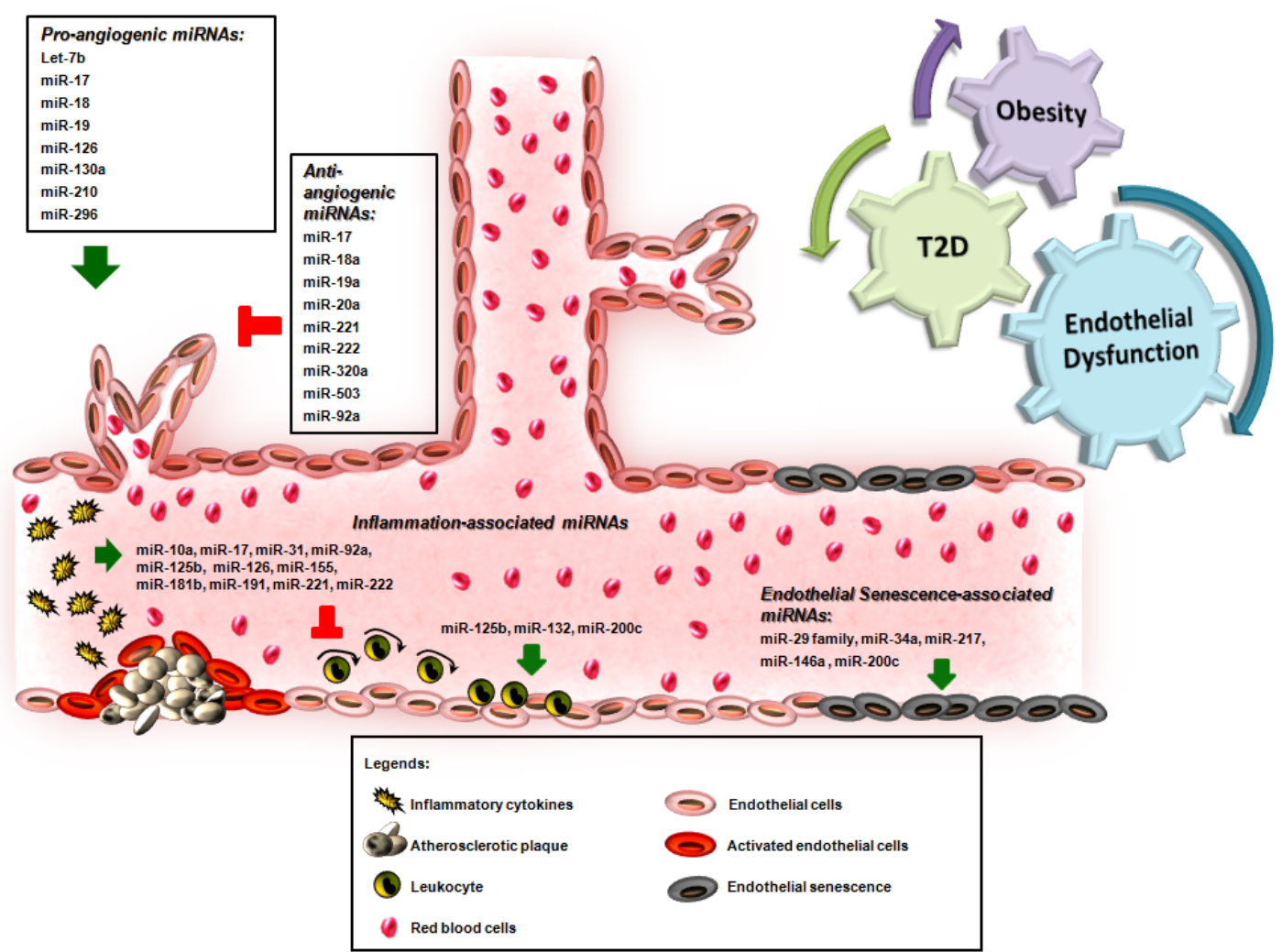

Figure 3: miRNA network in diabesity-associated endothelial dysfunction. Excess adiposity and diabetic condition induce changes in miRNA expression. Dysregulation of miRNAs affects endothelial function via three main processes: inflammation, angiogenesis and senescence. 
growth factor receptor 2 (VEGFR2), eNOS and IL-8 which also affect EC proliferation and cord formation [77]. Moreover, inactivation of Dicer also reduced postnatal angiogenic response to multiple stimuli such as exogenous VEGF or in models of tumorigenesis, limb ischemia as well as wound healing [78].

Inflammation-associated miRNAs: Excess adipose and hyperglycemia could induce alteration in the normal physiological state miRNA expression exacerbating the progression of vascular complications. Vascular inflammation is an early event in the progression of atherogenesis that is also the primary mechanism of endothelial dysfunction in diabesity. Accumulated adiposity leads to increased oxidative stress in adipose tissue and increased production of ROS and inflammatory chemokines which then promotes insulin resistance. Collectively, these processes induce the progression of endothelial dysfunction. Excess production of ROS and inflammatory adipokines eventually induce deregulation of inflammatory-associated miRNAs in the endothelium. Several studies have reported involvement of miRNAs in vascular inflammation by which they regulate leukocyte activation and infiltration through the vasculature $[79,80]$.

TNF- $\alpha$ treatment was found to induce the expression of miR31, miR-17, miR-191 and miR-125b in ECs [81]. SELE and ICAM1 were identified and subsequently validated as targets of miR-31 and miR-17-3p respectively. Specific inhibition of miR-31 and miR-17$3 p$ increased neutrophil adherence to TNF- $\alpha$ stimulation while overexpression of both miRNAs decreased TNF- $\alpha$ induced E-selectin (SELE) and ICAM1 expression hence reduced neutrophil adhesion to ECs [81]. TNF- $\alpha$ treatment also induced expression of miR-155, miR221/222 which co-targets Ets-1, a key endothelial transcription factor of inflammation and angiogenesis [82]. Stimulation with AngII in ECs up-regulated the expression of Ets-1, VCAM1, MCP1 and FLT1; overexpression with miR-155 or miR-221/miR-222 was able to reverse this effect. Specifically, over-expression of miR-155 and miR-221/ miR-222 inhibited leukocyte adhesion to ECs and EC migration [82]. Interestingly, miR-221/222 were observed to be up-regulated in obese rat adipocytes [83]. Not only that these miRNAs are responsible for inducing inflammatory adipo cytokines, their expression was found to correlate positively with TNF- $\alpha$ but negatively with adiponectin [84]. Furthermore, in vitro studies showed that miR-132 contributes to the inflammatory phenotype and macrophage infiltration by activating the inflammatory $\mathrm{NF}_{{ }_{\mathrm{K}}} \mathrm{B}$ pathway in adipocytes and inducing chemokine production [85]. Nonetheless, miR-132 expression in human visceral adipose tissue showed inverse correlation with macrophage infiltration as well as IL-6 levels in patients with non-alcoholic fatty liver disease $[86,87]$.

miR-126 is specifically and highly expressed in ECs thus often named as the guardian miRNA in ECs. miR-126 regulates inflammatory cell migration, capillary network formation and cell survival. Haris et al. [88] showed that miR-126 modulates vascular inflammation through inhibition of VCAM1 that is involved in leukocyte adhesion to ECs. Moreover, inhibition of miR-126 promotes pro-inflammatory TNF- $\alpha$ expression which then activates NF-KB and interferon regulatory factor 1. Consequently, this increases VCAM1 expression as well as leukocyte adhesion to ECs [88]. Likewise, miR-10a was reported to inhibit the NF-KB pathway by supressing the expression of MAP3K7 and $\beta T R C$ [89]. Moreover, the expression of miR-10a was reduced in athero-susceptible arterial regions alongside up-regulation of MAP3K7 and $\beta T R C$ suggesting its implication in regulating pro-inflammatory endothelial phenotypes in athero-susceptible regions [89]. miR-92a has also been found to be an atheroprotective miRNA. Knocking down this miRNA partially suppressed the inflammatory mediators, KLF2 and KLF4 and inhibited TNF- $\alpha$ induced leukocyte adhesion [90]. The expression of miR-181b was reduced in response to TNF. miR-181b regulates the expression of KPNA4, a protein crucial for translocation of $\mathrm{NF}_{-} \mathrm{B}$. Additionally, miR-181b has been shown to indirectly inhibit NF- ${ }_{\mathrm{K}} \mathrm{B}$ responsive genes, VCAM1 and SELE both in vitro and in vivo conditions [91]. Intravenous delivery of miR-181b mimics was found to reduce the NF- ${ }_{\mathrm{K}} \mathrm{B}$ pathway and therefore decreased lung injury and mortality in endotoxemic mice while inhibiting miR-181b activity resulted in the inflammatory phenotype [91].

A recent study using VSMCs of diabetic rats demonstrated upregulation of miR-200 family members, particularly miR-200b, miR$200 \mathrm{c}$ and miR-429 alongside down-regulation of their common target, $Z E B 1$ [92]. By using miR-200 mimics, the author observed decreased expression of $Z E B 1$ with a resultant enhanced transcription of the inflammatory $C O X-2$ and $M C P 1$ thereby promoting pro-inflammatory response [92]. Another independent study reported up-regulation of miR-125b in the VSMCs of diabetic rats as compared to control $\mathrm{db} /+$ mice [93]. Suv39h1 was identified as a target of miR-125b and that suppression of Suv39h1 by miR-125b induced the expression of inflammatory genes [93]. These data suggest the implication of miRNAs in eliciting pro-inflammatory responses of VSMCs thereby aggravating vascular complications in diabetic conditions.

Angiogenesis-associated miRNAs: Angiogenesis refers to the formation of new blood vessels via EC sprouting from preexisting vessels. This process is important in many physiological and pathological conditions, including embryonic development, wound healing, tissue regeneration and atherosclerosis. Emerging evidence shows that dysregulation of EC functions plays an important role in the subsequent aberrant angiogenic responses as diabesity progresses. A large number of miRNAs are involved in angiogenesis and they are often categorized into two groups; pro-angiogenic miRNAs and antiangiogenic miRNAs [94].

miR-126 is located in the intron of Egfl-7, an endothelial-specific protein implicated in vascular development [95]. miR-126 regulates various aspects of endothelial biology including cell migration, cytoskeleton organization and capillary network stability. Knockdown of miR-126 in zebrafish and mice resulted in loss of vascular integrity and angiogenic activity, impaired proliferation and migration, haemorrhage and partial embryonic lethality [96-98]. miR-126 regulates angiogenesis and vascular integrity by targeting multiple proteins such as SPRED1 and PIK3R2/p85-beta, both negative regulators of VEGF signalling [99]. Most importantly, loss of endothelial miR-126 is reported as a signature of T2D in which high glucose concentration was observed to reduce miR-126 expression in endothelial apoptotic bodies [100]. Interestingly, reduction in miR-126 level is detectable years before the appearance of diabetes and it correlates with subclinical and manifest peripheral artery disease [101]. The findings in this study have highlighted the good predictive and prognostic values of miRNAs for the onset of diabetic vascular complications. In addition, a more recent study reported down-regulation of miR-126, miR-130a, miR-21 and miR-27a/b in endothelial progenitor cells (EPCs) of T2D patients that contributes to impaired EPC function [102]. More indepth study revealed that decreased miR-130a impairs EPC function by targeting Runx3 and through ERK/VEGF and Akt pathways [102]. On another note, the expression of miR-130a although undetectable in quiescent HUVECs, became highly expressed upon exposure to fetal bovine serum [103]. miR-130a regulates expression of GAX and 
HoxA5 proteins which are inhibitors of angiogenesis [103]. These findings might provide insights to the mechanism underlying impaired angiogenic signalling in diabetic patients.

Other important pro-angiogenic miRNAs include miR-17-92 cluster, let-7 family, miR-210 and miR-296. The miR-17-92 cluster which encodes six miRNAs namely, miR-17, miR-18a, miR-19a, miR20a, miR-19b and miR-92a, is known to promote cell proliferation, suppresses cancer cell apoptosis and induces tumour angiogenesis [104]. Over-expression of this cluster of miRNAs by Myc-induced tumors enhanced angiogenesis through the down-regulation of anti-angiogenic proteins such as CTGF and Tsp-1, targets of miR18 and miR-19 respectively $[105,106]$. miR-17 was found to target the expression of the anti-angiogenic metalloproteinase inhibitor 1 (TIMP1) therefore affecting endothelial cell proliferation and motility [107]. The let-7 family is highly expressed in HUVECs and inhibition of let-7f specifically, was found to reduce sprout formation. Similar to miR-17, let-7b regulates EC proliferation and motility by suppressing the expression and activity of TIMP1 [107].

Fasanaro et al. [108] demonstrated up-regulation of miR-210 in ECs in response to hypoxia affects cell survival, migration and differentiation. The study also showed that over-expression of miR210 could promote primary capillary network formation and VEGFinduced cell migration while silencing miR-210 expression prevented the formation of capillaries as well as decreased cell migration in normoxic ECs [108]. A more recent work has identified miR-296 as a crucial element of the angiogenic process [109]. miR-296 expression is increased in primary cultures of human brain microvascular ECs subjected to angiogenic growth factors. Specific inhibition of miR-296 by antagomiRs resulted in decreased neovascularization of tumours in mice and also reduced angiogenesis in tumor xenografts in vivo [109]. Overall, these studies showed evidence for the pro-angiogenic role of miR-296.

A study by Poliseno et al. [110] proved that miR-221 and miR-222 are anti-angiogenic factors that inhibit EC migration, proliferation and angiogenesis in vitro by targeting stem cell factor (SCF) and c-Kit. In vivo, cells transfected with miR-221/miR-222 lost the ability to form tubes or to heal wounds in response to SCF. In support of his findings, Li et al. [111] reported increased miR-221 expression and reduced $\boldsymbol{c}$-kit expression in HUVECs subjected to high glucose while inhibiting miR-221 was able to reverse these effects. More importantly, internal mammary arteries of diabetic individuals were found to exhibit upregulation of miR-221/222 which are known to accelerate intimal thickening in animal models of vascular injury [112]. Elevation of miR-221/222 levels were observed alongside decreased expression of p2 $7^{\mathrm{Kip} 1}$ mRNA as well as increased VSMCs proliferation rate [112]. Interestingly, internal mammary arteries isolated from diabetic individuals receiving metformin treatment demonstrated a reversal of each of these factors. On another note, Dicer silencing has revealed miR-221/miR-222 to be implicated in regulating eNOS expression in the endothelium [77]. Nonetheless, since prediction sites for both miRNAs were not found in the 3'UTR of eNOS, the regulation of eNOS and $\mathrm{miR}-221 / \mathrm{miR}-222$ is considered to be indirect.

Adding on to the list of anti-angiogenic miRNAs are miR-320 and miR-503. Wang et al. [113] observed an increased expression of miR-320 in myocardial microvascular endothelial cells (MMVECs) of T2D rats. miR-320 may target several angiogenic factors and their receptors including VEGF-A, FGFs, IGF-1 and IGF-1R [114,115]. Specific inhibition of miR-320 in the myocardial microvascular ECs of diabetic rats was found to increase IGF-1 expression and improved cell proliferation and migration [116]. Nonetheless, a more recent study by Feng et al. [117] reported an opposing down-regulation of miR-320 in HUVECs subjected to high glucose alongside increased expression of ET-1,VEGF and fibronectin. The author also showed that transfection of miR-320 mimics restored the expression of the above mentioned vasoactive factors and ECM proteins. miR-503 was observed to be up-regulated in myocardial ECs of diabetic rats, in 3T3-L1 insulin-resistant adipocytes as well as in the muscles of T2D and insulin-resistant patients $[113,118,119]$. Over-expression of miR503 resulted in reduced proliferation, migration, and cell networking capacities while inhibiting its expression was able to restore normal EC proliferation and angiogenesis even in the presence of high glucose/ low growth factor conditions (a model of ischemia-induced tissue starvation in the context of diabetes) [120].

Interestingly, few studies have suggested certain miRNAs in the miR-17-92 cluster to have anti-angiogenic activity. Bonauer et al. [121] showed that miR-92a in ECs suppressed angiogenesis both in vitro and in vivo. Forced expression of miR-92a inhibited angiogenesis in ECs by targeting ITGa5 while administration of anatgomiR-92a prevented neovascularization in mouse hindlimb ischemia model and reduced tissue injury in myocardial infarction. Furthermore, over-expression of miR-17, miR-18a, miR-19a and miR-20a was found to inhibit endothelial sprouting in vivo [122]. These intriguing findings warrant further analysis to ascertain the role of individual miRNAs in this cluster with respect to angiogenesis.

Senescence-associated miRNAs: Obesity creates a chronic inflammatory state in the vascular wall which induces activation of the $\mathrm{NF}_{\mathrm{K}} \mathrm{B}$ pathway and production of pro-inflammatory cytokines. Prolonged exposure of the vasculature to such oxidative stress accelerates the development of endothelial senescence, a significant contributor of endothelial dysfunction. Similarly, chronic hyperglycemia has been postulated to accelerate vascular cellular senescence which has a crucial causative role in the development and progression of diabetic complications. Several miRNAs involved in endothelial senescence include miR-217, miR-34a, miR-146 and miR200c. miR-217, expressed in young HUVECs, human aortic endothelial cells and human coronary artery endothelial cells, promote endothelial senescence by suppressing the expression of silent information regulator 1 (SIRT1) [123]. SIRT1 is a NAD ${ }^{+}$-dependent deacetylase that prevents stress-induced senescence and mediates angiogenesis through deacetylation of the fork head transcription factor 1 (FOXO1) [123]. The other miRNA, miR-34a is expressed in primary ECs and its expression level increases upon cell senescence. miR-34a shares a similar function with miR-217 as a negative regulator of SIRT1 [124]. Independent studies showed that over-expression of mIR-217 and miR-34a in young ECs reduced SIRT1 expression and remarkably induced premature cell senescence [125]. A more recent study by VasaNicotera et al. [126] showed that miR-146a affects cellular senescence by inhibiting the expression of NOX4, the main isoform of the NADPH complex that catalyzes the reduction of molecular oxygen to ROS in the vessel wall. In addition to that, miR-200c was found to be up-regulated in response to ROS and this in turn induced endothelial cell apoptosis and senescence via ZEB1 inhibition [127]. On another note, non-obese rat model of T2D exhibited up-regulation of the miR-29 family in the insulin-responsive tissues; muscle, fat and liver [128]. Interestingly, over-expression of miR-29 in vitro in 3T3-L1 adipocytes is known to inhibit insulin and glucose responses. Hence, up-regulation of miR-29 might suggest impairment in insulin responsiveness and importantly, miR-29 is also up-regulated during cellular senescence [129]. Thus, modulating the expression of these miRNAs might serve as a novel 
therapeutic tool for delaying senescence in vascular disorders.

\section{Therapeutic Applications}

Various studies have shown that miRNAs may function as either positive or negative regulators of endothelial dysfunction by modulating their mRNA targets (Table 1). Hence normalizing the expression of the dysregulated miRNAs may serve as a therapeutic approach in controlling the development and/or progression of endothelial dysfunctions. Overexpressed miRNAs could be inhibited by introducing complementary anti-miRNA oligonucleotides (antagomiRs), while those miRNAs that are under-expressed could have their activity restored by synthetic miRNA mimics. The manipulation of miRNA expression comprises of two main approaches: miRNA inhibition therapy and miRNA replacement therapy.

Systemic inhibition of a certain miRNA can be done by administration of antisense oligonucleotides harboring the full or partial complementary reverse sequence of a mature miRNA. Generally, these antisense oligonucleotides could target the endogenous mature miRNA sequence to reduce the levels of pathogenic or aberrantly expressed miRNAs. Hence, the effect of miRNA antagonists is to relieve suppression on the target genes in other words, to promote gene activation. These synthesized miRNA inhibitors are typically known as antagomiRs with chemical modifications such as 2'Ome or 2'-MOE2 'F substitutions. The chemical modifications aid in enhancing cellular uptake as well as bioavailability in in vivo experiments and their activity has been shown to last up to 20 days [130]. An early study by Esau et al. [131] used 2'-MOE anti-miRNA oligonucleotides (AMO) to silence miR-122 in obese mice. Successful ablation of miR-122 resulted in reduced cholesterol content as well as decreased rates of hepatic fatty acid and cholesterol synthesis. Alternative approaches that have been proposed to block miRNA activity, at least in vitro, include miRNA sponges and microRNA erasers $[132,133]$. A miRNA sponge is typically an expression cassette containing a series of binding sites of the targeted miRNA that is included into the $3^{\prime}$ UTR of a reporter gene [134]. Unlike the miRNA sponge that induces a modest reduction of the endogenous miRNA, miRNA eraser has the capacity of inducing a significant loss of the miRNA activity. This is because miRNA erasers encompass tandem repeat of perfect complementary sequence of the target miRNA such that they are suppressed to a greater extent than transcripts containing imperfectly complementary targets [134]. In addition to antagomiRs, antimiRs employing the locked nucleic acid (LNA) technology have also shown great efficiency in silencing the expression of miRNAs of interest. In fact, this technology has been tested in a clinical trial under the drug name Miravirsen (Santaris Pharma A/S, Denmark) which also targets miR-122 for the treatment of hepatitis $\mathrm{C}$ virus (ClinicalTrials. gov identifier: NCT01200420). Miravirsen has just completed Phase II of the clinical trial and has thus far established safety, as well as its efficacy in inhibiting HCV disease progression.

Conversely, miRNA mimics can serve to enhance the expression levels of the naturally occurring miRNAs with salutary functions. While the miRNA inhibition methods are more commonly accepted and used, miRNA replacement therapy also presents an equally promising therapeutic approach. miRNA mimics contain the same sequence as the under-expressed endogenous miRNA with modifications for better stability and cellular uptake. These miRNA mimics are usually RNA duplexes with the 'guide strand' being identical to the target

\begin{tabular}{|c|c|c|c|}
\hline Endothelial cells & microRNAs & Target & Related biological function \\
\hline \multirow[t]{13}{*}{ Inflammation } & miR-10a [89] & MAP $3 K 7, \beta T R C$ & Pro-inflammatory response via NF-KB pathway \\
\hline & miR-125b [93] & Suv39h1 & Induction of inflammatory genes \\
\hline & miR-126 [88] & VCAM1 & Cell adhesion and interactions \\
\hline & miR-132 [85] & SIRT1 & Macrophage infiltration \\
\hline & miR-155 [82] & Ets1 & Cell migration and adhesion \\
\hline & $\operatorname{miR}-17[77]$ & ICAM1 & Cell migration and adhesion \\
\hline & $\operatorname{miR}-181 b[91]$ & KPNA4 & Translocation of NF-KB \\
\hline & $\mathrm{miR}-200 \mathrm{~b} / \mathrm{c}[92]$ & ZEB1 & Pro-inflammatory response \\
\hline & $\operatorname{miR}-221[82,110]$ & Ets-1, eNOS, c-kit & Cell proliferation and migration \\
\hline & miR-222 [82] [110] & Ets-1, eNOS, c-kit & Cell proliferation and migration \\
\hline & miR-31 [77] & SELE & Cell adhesion \\
\hline & $\operatorname{miR}-429$ [92] & ZEB1 & Pro-inflammatory response \\
\hline & miR-92a [90] & $K L F 2$ and $K L F 4$ & Cell adhesion \\
\hline \multirow[t]{12}{*}{ Angiogenesis } & let-7b [107] & TIMP1 & Cell proliferation and motility \\
\hline & miR-17 [107] & TIMP1 & Cell proliferation and motility \\
\hline & miR-18 [105] & CTGF & Cell proliferation and migration \\
\hline & miR-19 [106] & $T s p-1$ & Cell proliferation and migration \\
\hline & $\operatorname{miR}-210$ [108] & EFNA3 & Capillary network formation and cell migration \\
\hline & miR-296 [109] & HGS & Cell proliferation and migration \\
\hline & miR-126 [99] & SPRED1, PIK3R2/p85 $\beta$ & Cell proliferation and migration \\
\hline & miR-130a [103] & Runx3, GAX, HoxA5 & Cell proliferation and migration \\
\hline & $\operatorname{miR}-221 / 222[82,110]$ & SCF, c-Kit, eNOS & Cell proliferation, cell migration and vascular permeability \\
\hline & $\operatorname{miR}-320[116]$ & $I G F-1$ & Cell proliferation and migration \\
\hline & $\operatorname{miR}-503[113,120]$ & & Cell proliferation and migration \\
\hline & miR-92a [121] & ITGa5 & Cell proliferation and migration, endothelial sprouting \\
\hline \multirow[t]{4}{*}{ Cell senescence } & miR-34a [125] & SIRT1 & Premature cell senescence, stress resistance \\
\hline & miR-146a [126] & NOX4 & Cell proliferation \\
\hline & miR-200c [92] & ZEB1 & Cell apoptosis \\
\hline & $\operatorname{miR}-217$ [123] & SIRT1 & Premature cell senescence, stress resistance \\
\hline
\end{tabular}

Table 1: List of microRNAs implicated in endothelial function and their potential targets. 
endogenous miRNA and a modified 'passenger strand' for better cellular uptake. In a study by McArthur et al. [135], miR-200b, which targets $V E G F-A$, was found to be down-regulated in the retinas of diabetic rats. Transfection of miR-200b mimics in HUVECs subjected to high glucose conditions was able to attenuate VEGF-A mediated vascular permeability and tube formation. Subsequent in vivo experiments also proved that intravitreal injection of miR-200b mimics resulted in local decreased VEGF-A expression and vascular permeability in diabetic mice. Alternatively, miRNA expression can be increased using the adeno-associated viruses (AAVs) which allows constitutive expression of the miRNA of interest. This technique is employed in a study by Kota et al. [136] which demonstrated AAV-mediated delivery of miR26a could significantly diminish tumorigenesis in a mouse model of liver cancer. Most recently, anti-oncogenic function of miR-34 has been tested in a clinical trial under the drug name MRX34 (Mirna Therapeutics, Inc., USA). MRX34 is a liposome-formulated mimic of the tumor suppressor miRNA, miR-34, which is under-expressed in most malignancies (ClinicalTrials.gov identifier: NCT01829971). Overall, the successful miRNA-based studies in vitro, in vivo as well as the promising preliminary results from the ongoing clinical trials, show that manipulation of miRNA expression/activity holds a huge potential as therapeutic approach in diseases. Soon, miRNAs that could reverse vascular dysfunction in the laboratory bench would prove to be beneficial in clinical trials.

\section{Conclusions}

Endothelial dysfunction is a primary event in the progression of diabesity and often used as an early predictive marker of CVD. In addition, there is evidence that there exists a vicious cycle between obesity, hyperglycemia, insulin resistance and endothelial dysfunction. Insights into our understanding of the molecular mechanisms in endothelial dysfunction and the discovery of miRNAs implicated in these processes are useful in developing miRNA-based therapeutic strategy for vascular complications in diabesity. The revelation of miRNAs' roles in several pathologies has revolutionized the otherwise traditional way that scientists have been working on. The rapid pace of miRNA research and vast development in technology has led to the invention of suitable methodologies for detecting aberrant miRNA expression in diseases and sophisticated techniques to manipulate miRNA expression which may be used as novel therapeutic tools in the future. Numerous studies have reported various miRNAs which showed deregulated expression during the manifestation of metabolic disorders prior to clinical cardiovascular diseases [137]. Among these, reduced expression of miR-126 in particular, could be detected years before the appearance of diabetes and symptoms of related vascular diseases. These findings not only feature miRNAs as good markers for early diagnosis of cardiovascular events but also prompted several clinicians and scientists to assess the predictive value of other miRNAs in diabesity-induced vascular dysfunction. Early identification of cardiovascular events in obese and diabetic individuals raises the possibility for pharmacotherapy to delay progression and prevent future vascular complications. In addition, several studies have also demonstrated different methods of modulating miRNA expression and activity to treat vascular complications in obese/diabetic study models. With capacity to control gene expression and regulate over various biological pathways, miRNAs are definitely intriguing targets for novel therapeutic interventions, distinct from that of the classical single-drug-target strategy. Moreover, the stable existence of miRNAs in circulation has made them even more easily accessible for detection and thus serves as an effective platform for prevention, early diagnosis as well as treatment. Nonetheless, such therapeutic approach necessitates a detailed understanding of the molecular mechanisms regulated by the miRNAs of interest in the specific pathological condition, before proceeding into clinical applications.

\section{Acknowledgments}

The authors thank the National Medical Research Council (NMRC) Singapore for supporting this publication by the research grant, R-183-000-290-213.

\section{References}

1. Dandona $P$ (2002) Endothelium, inflammation, and diabetes. Curr Diab Rep 2: 311-315.

2. McVeigh GE, Cohn JN (2003) Endothelial dysfunction and the metabolic syndrome. Curr Diab Rep 3: 87-92.

3. Caballero AE (2003) Endothelial dysfunction in obesity and insulin resistance: a road to diabetes and heart disease. Obes Res 11: 1278-1289.

4. Friedman RC, Farh KK, Burge CB, Bartel DP (2009) Most mammalian mRNAs are conserved targets of microRNAs. Genome Res 19: 92-105.

5. Lim LP, Lau NC, Garrett-Engele P, Grimson A, Schelter JM, et al. (2005) Microarray analysis shows that some microRNAs downregulate large numbers of target mRNAs. Nature 433: 769-773.

6. Chamorro-Jorganes A, Araldi E, Suárez Y (2013) MicroRNAs as pharmacological targets in endothelial cell function and dysfunction. Pharmacol Res 75: 15-27.

7. Farag YM, Gaballa MR (2011) Diabesity: an overview of a rising epidemic Nephrol Dial Transplant 26: 28-35.

8. (1997) Report of the Expert Committee on the Diagnosis and Classification of Diabetes Mellitus. Diabetes Care 20: 1183-1197.

9. Quyyumi AA (1998) Endothelial function in health and disease: new insights into the genesis of cardiovascular disease. Am J Med 105: 32S-39S.

10. Kawashima S (2004) The two faces of endothelial nitric oxide synthase in the pathophysiology of atherosclerosis. Endothelium 11: 99-107.

11. Janssen-Heininger YM, Poynter ME, Baeuerle PA (2000) Recent advances towards understanding redox mechanisms in the activation of nuclear factor kappaB. Free Radic Biol Med 28: 1317-1327.

12. Cowan DB, Langille BL (1996) Cellular and molecular biology of vascular remodeling. Curr Opin Lipidol 7: 94-100.

13. Biegelsen ES, Loscalzo J (1999) Endothelial function and atherosclerosis Coron Artery Dis 10: 241-256

14. van den Oever IA, Raterman HG, Nurmohamed MT, Simsek S (2010) Endothelial dysfunction, inflammation, and apoptosis in diabetes mellitus. Mediators Inflamm 2010: 792393

15. Harrison DG (1997) Cellular and molecular mechanisms of endothelial cell dysfunction. J Clin Invest 100: 2153-2157.

16. Ross $R$ (1999) Atherosclerosis is an inflammatory disease. Am Heart J 138 : S419-420

17. Mano T, Masuyama T, Yamamoto K, Naito J, Kondo H, et al. (1996) Endothelia dysfunction in the early stage of atherosclerosis precedes appearance of intimal lesions assessable with intravascular ultrasound. Am Heart J 131: 231-238.

18. Caballero AE, Arora S, Saouaf R, Lim SC, Smakowski P, et al. (1999) Microvascular and macrovascular reactivity is reduced in subjects at risk for type 2 diabetes. Diabetes 48: 1856-1862.

19. Steinberg HO, Chaker H, Leaming R, Johnson A, Brechtel G, et al. (1996) Obesity/insulin resistance is associated with endothelial dysfunction Implications for the syndrome of insulin resistance. J Clin Invest 97: 2601-2610.

20. Pi-Sunyer FX (2002) The obesity epidemic: pathophysiology and consequences of obesity. Obes Res 2: 97S-104S.

21. Kahn BB, Flier JS (2000) Obesity and insulin resistance. J Clin Invest 106 473-481.

22. Goldstein BJ, Scalia RG, Ma XL (2009) Protective vascular and myocardial effects of adiponectin. Nat Clin Pract Cardiovasc Med 6: 27-35. 
Citation: Karolina DS, Silambarasan M, Armugam A, Jeyaseelan K (2014) MicroRNAs and Endothelial Dysfunction in Relation to Obesity and Type 2 Diabetes. J Mol Genet Med S1: 011. doi: 10.4172/1747-0862.S1-011

Page 10 of 12

23. Schalkwijk CG, Stehouwer CD (2005) Vascular complications in diabetes mellitus: the role of endothelial dysfunction. Clin Sci (Lond) 109: 143-159.

24. Ouchi N, Kihara S, Arita Y, Nishida M, Matsuyama A, et al. (2001) Adipocytederived plasma protein, adiponectin, suppresses lipid accumulation and class A scavenger receptor expression in human monocyte-derived macrophages. Circulation 103: 231-238.

25. Weyer C, Funahashi T, Tanaka S, Hotta K, Matsuzawa Y, et al. (2001) Hypoadiponectinemia in obesity and type 2 diabetes: close association with insulin resistance and hyperinsulinemia. J Clin Endocrinol Metab 86: 19301935.

26. Nagai N, Van Hoef B, Lijnen HR (2007) Plasminogen activator inhibitor-1 contributes to the deleterious effect of obesity on the outcome of thrombotic ischemic stroke in mice. J Thromb Haemost 5: 1726-1731.

27. Cox CL, Stanhope KL, Schwarz JM, Graham JL, Hatcher B, et al. (2011) Circulating concentrations of monocyte chemoattractant protein-1, plasminogen activator inhibitor-1, and soluble leukocyte adhesion molecule-1 in overweight/ obese men and women consuming fructose- or glucose-sweetened beverages for 10 weeks. J Clin Endocrinol Metab 96: E2034-E2038.

28. Tzanavari T, Giannogonas P, Karalis KP (2010) TNF-alpha and obesity. Curr Dir Autoimmun 11: 145-156.

29. Eder K, Baffy N, Falus A, Fulop AK (2009) The major inflammatory mediator interleukin-6 and obesity. Inflamm Res 58: 727-736.

30. Yamamoto K, Takeshita K, Kojima T, Takamatsu J, Saito H (2005) Aging and plasminogen activator inhibitor-1 (PAl-1) regulation: implication in the pathogenesis of thrombotic disorders in the elderly. Cardiovasc Res 66: 276285.

31. Steppan CM, Bailey ST, Bhat S, Brown EJ, Banerjee RR, et al. (2001) The hormone resistin links obesity to diabetes. Nature 409: 307-312.

32. Nagaev I, Smith U (2001) Insulin resistance and type 2 diabetes are not related to resistin expression in human fat cells or skeletal muscle. Biochem Biophys Res Commun 285: 561-564.

33. Pastore L, Tessitore A, Martinotti S, Toniato E, Alesse E, et al. (1999) Angiotensin II stimulates intercellular adhesion molecule-1 (ICAM-1) expression by human vascular endothelial cells and increases soluble ICAM-1 release in vivo. Circulation 100: 1646-1652.

34. Rajagopalan S, Kurz S, Munzel T, Tarpey M, Freeman BA, et al. (1996) Angiotensin II-mediated hypertension in the rat increases vascular superoxide production via membrane NADH/NADPH oxidase activation. Contribution to alterations of vasomotor tone. J Clin Invest 97: 1916-1923.

35. Touyz RM (2004) Reactive oxygen species and angiotensin II signaling in vascular cells -- implications in cardiovascular disease. Braz J Med Biol Res 37: 1263-1273.

36. Folli F, Kahn CR, Hansen H, Bouchie JL, Feener EP (1997) Angiotensin II inhibits insulin signaling in aortic smooth muscle cells at multiple levels. A potential role for serine phosphorylation in insulin/angiotensin II crosstalk. J Clin Invest 100: 2158-2169.

37. Andreozzi F, Laratta E, Sciacqua A, Perticone F, Sesti G (2004) Angiotensin II impairs the insulin signaling pathway promoting production of nitric oxide by inducing phosphorylation of insulin receptor substrate-1 on Ser312 and Ser616 in human umbilical vein endothelial cells. Circ Res 94: 1211-1218.

38. Aguirre V, Uchida T, Yenush L, Davis R, White MF (2000) The c-Jun $\mathrm{NH}(2)$ terminal kinase promotes insulin resistance during association with insulin receptor substrate-1 and phosphorylation of Ser(307). J Biol Chem 275: 9047 9054.

39. De Fea K, Roth RA (1997) Protein kinase C modulation of insulin receptor substrate-1 tyrosine phosphorylation requires serine 612 . Biochemistry 36 : 12939-12947.

40. Zeng M, Zhang H, Lowell C, He P (2002) Tumor necrosis factor-alpha-induced leukocyte adhesion and microvessel permeability. Am J Physiol Heart Circ Physiol 283: H2420-2430.

41. Ashton AW, Ware GM, Kaul DK, Ware JA (2003) Inhibition of tumor necrosis factor alpha-mediated NFkappaB activation and leukocyte adhesion, with enhanced endothelial apoptosis, by G protein-linked receptor (TP) ligands. J Biol Chem 278: 11858-11866.

42. Park SH, Park JH, Kang JS, Kang YH (2003) Involvement of transcription factors in plasma HDL protection against TNF-alpha-induced vascular cell adhesion molecule-1 expression. Int J Biochem Cell Biol 35: 168-182.

43. Uzui H, Harpf A, Liu M, Doherty TM, Shukla A, et al. (2002) Increased expression of membrane type 3-matrix metalloproteinase in human atherosclerotic plaque: role of activated macrophages and inflammatory cytokines. Circulation 106 3024-3030.

44. Pasceri V, Willerson JT, Yeh ET (2000) Direct proinflammatory effect of C-reactive protein on human endothelial cells. Circulation 102: 2165-2168.

45. Venugopal SK, Devaraj S, Yuhanna I, Shaul P, Jialal I (2002) Demonstration that C-reactive protein decreases eNOS expression and bioactivity in human aortic endothelial cells. Circulation 106: 1439-1441.

46. Suzuki K, Nakaji S, Yamada M, Totsuka M, Sato K, et al. (2002) Systemic inflammatory response to exhaustive exercise. Cytokine kinetics. Exerc Immunol Rev 8: 6-48.

47. Starkie R, Ostrowski SR, Jauffred S, Febbraio M, Pedersen BK (2003) Exercise and IL-6 infusion inhibit endotoxin-induced TNF-alpha production in humans. FASEB 17: 884-886

48. Qatanani M, Lazar MA (2007) Mechanisms of obesity-associated insulin resistance: many choices on the menu. Genes Dev 21: 1443-1455.

49. Juhan-Vague I, Alessi MC, Mavri A, Morange PE (2003) Plasminogen activato inhibitor-1, inflammation, obesity, insulin resistance and vascular risk. J Thromb Haemost 1: 1575-1579.

50. Rieusset J, Bouzakri K, Chevillotte E, Ricard N, Jacquet D, et al. (2004) Suppressor of cytokine signaling 3 expression and insulin resistance in skeletal muscle of obese and type 2 diabetic patients. Diabetes 53: 2232-2241.

51. Ryden M, Dicker A, van Harmelen V, Hauner H, Brunnberg M, et al. (2002) Mapping of early signaling events in tumor necrosis factor-alpha -mediated lipolysis in human fat cells. J Biol Chem 277: 1085-1091.

52. Ruan H, Lodish HF (2003) Insulin resistance in adipose tissue: direct and indirect effects of tumor necrosis factor-alpha. Cytokine Growth Factor Rev 14 447-455.

53. Montagnani M, Chen H, Barr VA, Quon MJ (2001) Insulin-stimulated activation of eNOS is independent of $\mathrm{Ca2}+$ but requires phosphorylation by Akt at Ser(1179). J Biol Chem 276: 30392-30398.

54. Kuboki K, Jiang ZY, Takahara N, Ha SW, Igarashi M, et al. (2000) Regulation of endothelial constitutive nitric oxide synthase gene expression in endothelia cells and in vivo : a specific vascular action of insulin. Circulation 101: 676-681.

55. Jiang ZY, Lin YW, Clemont A, Feener EP, Hein KD, et al. (1999) Characterization of selective resistance to insulin signaling in the vasculature of obese Zucker (fa/fa) rats. J Clin Invest 104: 447-457.

56. Montagnani M, Golovchenko I, Kim I, Koh GY, Goalstone ML, et al. (2002) Inhibition of phosphatidylinositol 3-kinase enhances mitogenic actions of insulin in endothelial cells. J Biol Chem 277: 1794-1799.

57. Wheatcroft SB, Williams IL, Shah AM, Kearney MT (2003) Pathophysiologica implications of insulin resistance on vascular endothelial function. Diabet Med 20: $255-268$

58. Calles-Escandon J, Cipolla M (2001) Diabetes and endothelial dysfunction: a clinical perspective. Endocr Rev 22: 36-52.

59. Nishikawa T, Edelstein D, Du XL, Yamagishi S, Matsumura T, et al. (2000) Normalizing mitochondrial superoxide production blocks three pathways of hyperglycaemic damage. Nature 404: 787-790.

60. Brownlee M (2001) Biochemistry and molecular cell biology of diabetic complications. Nature 414: 813-820.

61. Williams B, Gallacher B, Patel H, Orme C (1997) Glucose-induced protein kinase $C$ activation regulates vascular permeability factor mRNA expression and peptide production by human vascular smooth muscle cells in vitro. Diabetes 46: 1497-1503.

62. Dagher Z, Park YS, Asnaghi V, Hoehn T, Gerhardinger C, et al. (2004) Studies of rat and human retinas predict a role for the polyol pathway in human diabetic retinopathy. Diabetes 53: 2404-2411.

63. Gabbay KH (1975) Hyperglycemia, polyol metabolism, and complications of diabetes mellitus. Annu Rev Med 26: 521-536.

64. Goldin A, Beckman JA, Schmidt AM, Creager MA (2006) Advanced glycation 
Citation: Karolina DS, Silambarasan M, Armugam A, Jeyaseelan K (2014) MicroRNAs and Endothelial Dysfunction in Relation to Obesity and Type 2 Diabetes. J Mol Genet Med S1: 011. doi: 10.4172/1747-0862.S1-011

end products: sparking the development of diabetic vascular injury. Circulation 114: 597-605.

65. Schmidt AM, Hori O, Brett J, Yan SD, Wautier JL, Stern D (1994) Cellula receptors for advanced glycation end products. Implications for induction of oxidant stress and cellular dysfunction in the pathogenesis of vascular lesions. Arterioscler Thromb 14: 1521-1528.

66. Kim VN (2005) MicroRNA biogenesis: coordinated cropping and dicing. Na Rev Mol Cell Biol 6: 376-385.

67. Kim VN, Nam JW (2006) Genomics of microRNA. Trends Genet 22: 165-173.

68. Bartel DP (2004) MicroRNAs: genomics, biogenesis, mechanism, and function Cell 116: 281-297.

69. Valencia-Sanchez MA, Liu J, Hannon GJ, Parker R (2006) Control of translation and mRNA degradation by miRNAs and siRNAs. Genes Dev 20: 515-524.

70. Place RF, Li LC, Pookot D, Noonan EJ, Dahiya R (2008) MicroRNA-373 induces expression of genes with complementary promoter sequences. Proc Natl Acad Sci U S A 105: 1608-1613.

71. Majid S, Dar AA, Saini S, Yamamura S, Hirata H, et al. (2010) MicroRNA205-directed transcriptional activation of tumor suppressor genes in prostate cancer Cancer 116: 5637-5649.

72. Karolina DS, Armugam A, Sepramaniam S, Jeyaseelan K (2012) miRNAs and diabetes mellitus Expert Rev Endocrinol Metab 7: 301-308

73. Shantikumar S, Caporali A, Emanueli C (2012) Role of microRNAs in diabetes and its cardiovascular complications. Cardiovasc Res 93: 583-593.

74. Quiat D, Olson EN (2013) MicroRNAs in cardiovascular disease: from pathogenesis to prevention and treatment. J Clin Invest 123: 11-18.

75. Williams MD, Mitchell GM (2012) MicroRNAs in insulin resistance and obesity. Exp Diabetes Res 2012: 484696.

76. Yang WJ, Yang DD, Na S, Sandusky GE, Zhang Q, et al. (2005) Dicer is required for embryonic angiogenesis during mouse development. J Biol Chem 280: 9330-9335

77. Suárez Y, Fernández-Hernando C, Pober JS, Sessa WC (2007) Dicer dependent microRNAs regulate gene expression and functions in human endothelial cells. Circ Res 100: 1164-1173.

78. Suarez Y, Fernandez-Hernando C, Yu J, Gerber SA, Harrison KD, et al. (2008) Dicer-dependent endothelial microRNAs are necessary for postnata angiogenesis. Proc Natl Acad Sci U S A 105: 14082-14087.

79. Yamakuchi M (2012) MicroRNAs in Vascular Biology. Int J Vasc Med 2012 794898.

80. Staszel T, Zapała B, Polus A, Sadakierska-Chudy A, Kieć-Wilk B, et al. (2011) Role of microRNAs in endothelial cell pathophysiology. Pol Arch Med Wewn 121: 361-366.

81. Suarez Y, Wang C, Manes TD, Pober JS (2010) Cutting edge: TNF-induced microRNAs regulate TNF-induced expression of E-selectin and intercellular adhesion molecule-1 on human endothelial cells: feedback control of inflammation. J Immunol 184: 21-25.

82. Zhu N, Zhang D, Chen S, Liu X, Lin L, et al. (2011) Endothelial enriched microRNAs regulate angiotensin II-induced endothelial inflammation and migration. Atherosclerosis 215: 286-293.

83. Ortega FJ, Moreno-Navarrete JM, Pardo G, Sabater M, Hummel M, et al. (2010) MiRNA expression profile of human subcutaneous adipose and during adipocyte differentiation. PloS one 5: e9022.

84. Parra P, Serra F, Palou A (2010) Expression of adipose microRNAs is sensitive to dietary conjugated linoleic acid treatment in mice. PLoS One 5: e13005.

85. Strum JC, Johnson JH, Ward J, Xie H, Feild J, et al. (2009) MicroRNA 132 regulates nutritional stress-induced chemokine production through repression of SirT1. Mol Endocrinol 23: 1876-1884

86. Klöting N, Berthold S, Kovacs P, Schön MR, Fasshauer M, et al. (2009) MicroRNA expression in human omental and subcutaneous adipose tissue. PLoS One 4: e4699.

87. Estep M, Armistead D, Hossain N, Elarainy H, Goodman Z, et al. (2010) Differential expression of miRNAs in the visceral adipose tissue of patients with non-alcoholic fatty liver disease. Aliment Pharmacol Ther 32: 487-497.
88. Harris TA, Yamakuchi M, Ferlito M, Mendell JT, Lowenstein CJ (2008) MicroRNA-126 regulates endothelial expression of vascular cell adhesion molecule 1. Proc Natl Acad Sci U S A 105: 1516-1521.

89. Fang Y, Shi C, Manduchi E, Civelek M, Davies PF (2010) MicroRNA-10a regulation of proinflammatory phenotype in athero-susceptible endothelium in vivo and in vitro. Proc Natl Acad Sci U S A 107: 13450-13455

90. Fang Y, Davies PF (2012) Site-specific microRNA-92a regulation of Kruppellike factors 4 and 2 in atherosusceptible endothelium. Arterioscler Thromb Vasc Biol 32: 979-987.

91. Sun X, Icli B, Wara AK, Belkin N, He S, et al. (2012) MicroRNA-181b regulates NF-Î०B-mediated vascular inflammation. J Clin Invest 122: 1973-1990.

92. Reddy MA, Jin W, Villeneuve L, Wang M, Lanting L, et al. (2012) Proinflammatory role of microrna-200 in vascular smooth muscle cells from diabetic mice. Arterioscler Thromb Vasc Biol 32: 721-729.

93. Villeneuve LM, Kato M, Reddy MA, Wang M, Lanting L, et al. (2010) Enhanced levels of microRNA-125b in vascular smooth muscle cells of diabetic $\mathrm{db} / \mathrm{db}$ mice lead to increased inflammatory gene expression by targeting the histone methyltransferase Suv39h1. Diabetes 59: 2904-2915.

94. Wu F, Yang Z, Li G (2009) Role of specific microRNAs for endothelial function and angiogenesis. Biochem Biophys Res Commun 386: 549-553.

95. Parker LH, Schmidt M, Jin SW, Gray AM, Beis D, Pham T, Frantz G, Palmieri S Hillan K, Stainier DY, De Sauvage FJ, Ye W (2004) The endothelial-cell-derived secreted factor Egfl7 regulates vascular tube formation. Nature 428: 754-758.

96. Fish JE, Santoro MM, Morton SU, Yu S, Yeh RF, et al. (2008) miR-126 regulates angiogenic signaling and vascular integrity. Dev Cell 15: 272-284.

97. Wang S, Aurora AB, Johnson BA, Qi X, McAnally J, et al. (2008) The endothelialspecific microRNA miR-126 governs vascular integrity and angiogenesis. Dev Cell 15: 261-271.

98. Kuhnert F, Mancuso MR, Hampton J, Stankunas K, Asano T, et al. (2008) Attribution of vascular phenotypes of the murine Egfl7 locus to the microRNA miR-126. Development 135: 3989-3993.

99. Wakioka T, Sasaki A, Kato R, Shouda T, Matsumoto A, et al. (2001) Spred is a Sprouty-related suppressor of Ras signalling. Nature 412: 647-651.

100.Zampetaki A, Kiechl S, Drozdov I, Willeit P, Mayr U, et al. (2010) Plasma microRNA profiling reveals loss of endothelial miR-126 and other microRNAs in type 2 diabetes. Circ Res 107: 810-817.

101. Regazzi R (2010) Diabetes mellitus reveals its micro-signature. Circ Res 107 686-688.

102. Meng S, Cao J, Zhang X, Fan Y, Fang L, et al. (2013) Downregulation of microRNA-130a contributes to endothelial progenitor cell dysfunction in diabetic patients via its target Runx3. PLoS One 8: e68611.

103. Chen Y, Gorski DH (2008) Regulation of angiogenesis through a microRNA (miR-130a) that down-regulates antiangiogenic homeobox genes GAX and HOXA5. Blood 111: 1217-1226.

104. Mendell JT (2008) miRiad roles for the miR-17-92 cluster in development and disease. Cell 133: 217-222.

105.Dews M, Homayouni A, Yu D, Murphy D, Sevignani C, et al. (2006) Augmentation of tumor angiogenesis by a Myc-activated microRNA cluster. Nat Genet 38: 1060-1065.

106. Armstrong LC, Bornstein P (2003) Thrombospondins 1 and 2 function as inhibitors of angiogenesis. Matrix Biol 22: 63-71.

107. Otsuka M, Zheng M, Hayashi M, Lee JD, Yoshino O, et al. (2008) Impaired microRNA processing causes corpus luteum insufficiency and infertility in mice. J Clin Invest 118: 1944-1954.

108. Fasanaro P, D'Alessandra Y, Di Stefano V, Melchionna R, Romani S, et al (2008) MicroRNA-210 modulates endothelial cell response to hypoxia and inhibits the receptor tyrosine kinase ligand Ephrin-A3. J Biol Chem 283: 15878-15883.

109. Würdinger T, Tannous BA, Saydam O, Skog J, Grau S, et al. (2008) miR296 regulates growth factor receptor overexpression in angiogenic endothelia cells. Cancer Cell 14:382-393.

110. Poliseno L, Tuccoli A, Mariani L, Evangelista M, Citti L, et al. (2006) MicroRNAs modulate the angiogenic properties of HUVECs. Blood 108: 3068-3071. 
Citation: Karolina DS, Silambarasan M, Armugam A, Jeyaseelan K (2014) MicroRNAs and Endothelial Dysfunction in Relation to Obesity and Type 2 Diabetes. J Mol Genet Med S1: 011. doi: 10.4172/1747-0862.S1-011

111. Li Y, Song YH, Li F, Yang T, Lu YW, et al. (2009) MicroRNA-221 regulates high glucose-induced endothelial dysfunction. Biochem Biophys Res Commun 381: 81-83.

112. Coleman CB, Lightell DJ Jr, Moss SC, Bates M, Parrino PE, et al. (2013) Elevation of miR-221 and -222 in the internal mammary arteries of diabetic subjects and normalization with metformin. Mol Cell Endocrinol 374: 125-129.

113. Wang XH, Qian RZ, Zhang W, Chen SF, Jin HM, et al. (2009) MicroRNA-320 expression in myocardial microvascular endothelial cells and its relationship with insulin-like growth factor- 1 in type 2 diabetic rats. Clin Exp Pharm Physiol 36: 181-188.

114. Lewis BP, Shih IH, Jones-Rhoades MW, Bartel DP, Burge CB (2003) Prediction of mammalian microRNA targets. Cell 115: 787-798.

115. John B, Enright AJ, Aravin A, Tuschl T, Sander C, et al. (2004) Human MicroRNA targets. PLoS Biol 2: e363.

116. Rabinovsky ED, Draghia-Akli R (2004) Insulin-like growth factor I plasmid therapy promotes in vivo angiogenesis. Mol Ther 9: 46-55.

117. Feng B, Chakrabarti S (2012) miR-320 Regulates Glucose-Induced Gene Expression in Diabetes. ISRN Endocrinol 2012: 549875

118. Ling HY, Ou HS, Feng SD, Zhang XY, Tuo QH, et al. (2009) CHANGES IN microRNA (miR) profile and effects of miR-320 in insulin-resistant 3T3-L1 adipocytes. Clin Exp Pharmacol Physiol 36: e32-39.

119. Gallagher IJ, Scheele C, Keller P, Nielsen AR, Remenyi J, et al. (2010) Integration of microRNA changes in vivo identifies novel molecular features of muscle insulin resistance in type 2 diabetes. Genome Med 2: 9.

120. Caporali A, Meloni M, Vollenkle C, Bonci D, Sala-Newby GB, et al. (2011) Deregulation of microRNA-503 contributes to diabetes mellitus-induced impairment of endothelial function and reparative angiogenesis after limb ischemia. Circulation 123: 282-291.

121. Bonauer A, Carmona G, Iwasaki M, Mione M, Koyanagi M, et al. (2009) MicroRNA-92a controls angiogenesis and functional recovery of ischemic tissues in mice. Science 324: 1710-1713.

122. Doebele C, Bonauer A, Fischer A, Scholz A, Reiss Y, et al. (2010) Members of the microRNA-17-92 cluster exhibit a cell-intrinsic antiangiogenic function in endothelial cells. Blood 115: 4944-4950.

123. Menghini R, Casagrande V, Cardellini M, Martelli E, Terrinoni A, et al. (2009) MicroRNA 217 modulates endothelial cell senescence via silent information regulator 1. Circulation 120: 1524-1532.
124. Ito T, Yagi S, Yamakuchi M (2010) MicroRNA-34a regulation of endothelial senescence. Biochem Biophys Res Commun 398: 735-740.

125. Zhao T, Li J, Chen AF (2010) MicroRNA-34a induces endothelial progenitor cel senescence and impedes its angiogenesis via suppressing silent information regulator 1. Am J Physiol Endocrinol Metab 299: E110-116.

126. Vasa-Nicotera M, Chen $H$, Tucci $P$, Yang AL, Saintigny $G$, et al. (2011) miR$146 a$ is modulated in human endothelial cell with aging. Atherosclerosis 217 : 326-330.

127. Magenta A, Cencioni C, Fasanaro P, Zaccagnini G, Greco S, et al. (2011) miR$200 \mathrm{c}$ is upregulated by oxidative stress and induces endothelial cell apoptosis and senescence via ZEB1 inhibition. Cell Death Differ 18: 1628-1639.

128. He A, Zhu L, Gupta N, Chang Y, Fang F (2007) Overexpression of micro ribonucleic acid 29, highly up-regulated in diabetic rats, leads to insulin resistance in 3T3-L1 adipocytes. Mol Endocrinol 21: 2785-2794.

129. Martinez I, Cazalla D, Almstead LL, Steitz JA, DiMaio D (2011) miR-29 and miR-30 regulate B-Myb expression during cellular senescence. Proc Natl Acad Sci U S A 108: 522-527.

130. Krützfeldt J, Rajewsky N, Braich R, Rajeev KG, Tuschl T, et al. (2005) Silencing of microRNAs in vivo with 'antagomirs'. Nature 438: 685-689.

131. Esau C, Davis S, Murray SF, Yu XX, Pandey SK, et al. (2006) miR-122 regulation of lipid metabolism revealed by in vivo antisense targeting. Cell Metab 3: 87-98.

132. Ebert MS, Neilson JR, Sharp PA (2007) MicroRNA sponges: competitive inhibitors of small RNAs in mammalian cells. Nat Methods 4: 721-726.

133. Sayed D, Rane S, Lypowy J, He M, Chen IY, et al. (2008) MicroRNA-21 targets Sprouty2 and promotes cellular outgrowths. Mol Biol Cell 19: 3272-3282.

134.van Rooij E (2011) The art of microRNA research. Circ Res 108: 219-234.

135. McArthur K, Feng B, Wu Y, Chen S, Chakrabarti S (2011) MicroRNA-200b regulates vascular endothelial growth factor-mediated alterations in diabetic retinopathy. Diabetes 60: 1314-1323.

136. Kota J, Chivukula RR, O'Donnell KA, Wentzel EA, Montgomery CL, et al (2009) Therapeutic microRNA delivery suppresses tumorigenesis in a murine liver cancer model. Cell 137: 1005-1017.

137. Hulsmans M, Holvoet $P$ (2013) MicroRNAs as early biomarkers in obesity and related metabolic and cardiovascular diseases. Curr Pharm Des 19: 57045717. 